\title{
Class Representatives and Students' Behaviour: An Overview at the Post-Covid-19 Pandemic in the Perspective of the Community of Practice
}

Ilane Frank Dias: Business Lecturer and Research Associate, Oxford Business College, Oxford, United Kingdom.

־Christiane Bellucci: Business Lecturer and Research Associate, Oxford Business College, Oxford, United Kingdom.

\begin{abstract}
Engagement of students and the learning process in the classroom has become one of the significant challenges that higher education (HE) institutions face in the era of the Covid-19 pandemic, with classes running in the virtual environment. One of the approaches that can be used to understand student behaviours and their social interactions is the community of practice (CoPs) as a construct that can be strategic to connect classes representatives, college's objectives and the student's behaviour. The class representatives can play a diverse role, from helping the tutors motivate the students on their learning process to acting as a central and essential communication channel between the students and the academic coordinators. Yet, little is known about the role of these students as a strategy to tackle such problems increased with online classes. This study investigates the impact of class representatives on students' behaviour in the sense of their engagement and learning in virtual classes context post the Covid-19 pandemic. This is a conceptual paper to bridge the mentioned theories, link work across disciplines, provide multi-level insights, and broaden the scope of thinking. The theoretical findings show that class representatives can play a relevant role by increasing engagement and facilitating the students' learning. The results can help HE institutions to develop policies and practices to be more competitive and move forward. This study advances the emergent research efforts to respond to the challenges arising from the Covid-19 pandemic.
\end{abstract}

Key words: Community of practice, Covid-19, Engagement, Learning, Class representatives, Higher education institutions, Higher education students, Virtual classes, Social interaction, Governance.

JEL Classification: I23.

\section{Introduction}

Video lecturers have become very popular in education and are considered "effective means for delivering course content and infusing teaching presence in the virtual environment" (Scagnoli, Choo, \& Tian, 2019).

After the World Health Organization has declared the world pandemic at the beginning of 2020 (WHO, 2020) all classes had to shift to an online environment with schools and universities being physically closed. In this new and unexpected context, higher education institutions face big problems with engagement and, consequently, in the students' learning process during virtual classes (Bao, 2020; Basal \& Eryilmaz, 2021; Noor, Ali, \& Husnine, 2020). 
In learning environments, engagement has been formally defined as "learner's interest and participation in an educational initiative and is directly related to favourable educational outcomes including learning and behavioural change" (Carlson, 2020).

Recent studies have presented several strategies that can help design successful online study sessions and play a fundamental role in enhancing student learning and engagement (Bao, 2020; Daniels, Goegan, \& Parker, 2021).

However, little is known about the impact of the classes' representatives on the students' engagement and learning when in higher education in the context of virtual classes, which potentially increased after the Covid-19 pandemic. Would this role be only a symbolic representation, or could their participation in the college's governance be a strategy to effectively impact the student's behaviour? For this study, we take the Community of Practice (CoPs) perspective to answer the research question: May class representatives impact students' behaviour in the sense of their engagement and learning in virtual classes context?

This study highlights the CoPs of Wenger (2009) as a concept used to understand social structures capable of reproducing and transforming knowledge and providing learning opportunities for its members.

The results of Gómez and Suárez (2021) show an indirect connection between the community of practice and learning in the virtual environment during the Covid-19 Pandemic, which is still to be explored. In addition, Gómez and Suárez (2021) have shown the steady growth of academic publications on CoPs in higher education from 1991 to 2021. However, despite this steady growth in publications and claims about their benefits for faculty and students, empirical evidence of the impact of CoPs on teaching and learning is scarce.

This is a conceptual paper once it aims to "bridge existing theories in interesting ways, link work across disciplines, provide multi-level insights, and broaden the scope of our thinking" (Gilson \& Goldberg, 2015). Drawing on multiple concepts, literature streams, and theories that play differing roles, this study assimilates and combines evidence in the form of previously developed concepts and theories. Hence, we conceptually integrate (theories used) to generate novel insights by linking previously unconnected or incompatible pieces (Jaakkola, 2020).

By summarising and integrating extant knowledge of the presented concepts, this research contributes to private higher education institutions that can use such information to deliver better services and have better results through virtual classes with the help of these representatives. Nevertheless, this research contributes by advancing the emerging literature about online learning in the actual pandemic scenario and contributing to understanding the services provided by high education organisations.

\section{Literature Review}

\subsection{Communities of Practice (CoPs), a Social Theory of Learning}

Our approach in this conceptual research is based on Wenger (2009) community of practice once we want to understand the student behaviour that is based on their engagement in communities and organisations, such as HE institutions. Hence, we believe that learning is an integral part of students' everyday lives and is connected with their engagement with their group and the institutions they study. According to the Gómez and Suárez (2021) there is an indirect connection between the community of practice and learning in the virtual environment during Covid-19 Pandemic.

The social theory of learning presented by Wenger (2009) brings the community of practice as the learning process that is most personally transformative for students, involving membership in various groups. Levels of participation as a support for the learning process imply different perspectives, such as for individuals, communities and organisations. In the case of individuals, "learning is an issue of engaging in and contributing to the practices of their communities". If we talk about communities, it is "an issue of refining their practice and ensuring new generations of members". As in organisations, it means that "learning is an issue of sustaining the interconnected communities of practice through which an organisation knows what it knows and thus becomes effective and valuable as an organisation" (Wenger, 2009).

Since 1991, the year of its introduction (Lave \& Wenger, 1991) the community of practice as a construct has provided theoretical guidance to understand "how knowledge, learning, and skills are enabled, shaped, and advanced by social structures and informal interactions between individuals" (Gómez \& Suárez, 2021).

The community of practice approach is considered by authors in all areas and organisations (Akinyemi, Rembe, Shumba, \& Adewumi, 2019; Bond \& Lockee, 2018; Flint \& O’Hara, 2013; Lizzio \& Wilson, 2009; 
Pyrko, Dörfler, \& Eden, 2019). Moreover, such studies are applied in education to understand the social interactions in the academic field, whether institutionalised or not.

Concerning the classes representatives, which is the focus of this study, Lizzio and Wilson (2009) investigated the factors that such students perceived to help or hinder their effectiveness as student members of departmental committees. Students from various disciplines were interviewed about their experiences in the student representative' role on their approach. In conclusion, they pointed out that ambiguity of the role was the most significant challenge reported by student representatives, and the overall effectiveness of the role was perceived to be reliant on the disposition and ability of academic managers and staff to engage in constructive dialogue with students. Thus, it is argued that universities need to adopt a more proactive approach to developing and supporting student leaders and representatives.

Flint and O'Hara (2013) explored how far the theoretical model of a community of practice (Wenger 2002) can be applied to student representatives better to understand the relationship between students and their institution. Their study shows ways of building a sense of community amongst student representatives and faculty level staff in a higher education institution in the UK.

The study proposed a critical approach to creating the conditions for Higher Education institutions in allowing the actions of communities of practice amongst students and staff. It highlights the role of the students playing as decision-makers. It brings one of the fundamental principles of the communities of practice, where community members have a shared purpose. Student representatives and university staff have a clear pursuit of higher education, with different roles and focus, so, whilst they may have different perspectives on their aims, members of the community have a shared aim of quality enhancement: facilitating a high-quality university experience for students (Flint \& O’Hara, 2013)

\subsection{Communities of Practice in Organisational Level: An Engagement Strategy Tool}

Wenger, McDermott, and Snyder (2002) also apply the communities of practice approach at an organisational level. They considered that keeping communities of practice in organisations is a way to manage knowledge systematically, as the explosion of science and technology creates a paradox: while the growing complexity of knowledge requires greater specialisation and collaboration. Moreover, the vulnerability of knowledge makes it challenging to keep up with the rapid pace of change. From that perspective, it can show the three elements presented by the authors as a practical model to guide community development (Wenger et al., 2002):

1. Ownership - the job of negotiating shared ownership is critical to community development. A community must ask itself: what topics and issues really concern it?

2. Community - the community element needs attention, organisation and education. What roles will people play?

3. Practice - any community with sustained interactions will develop some kind of practice over time. What knowledge will you share, develop, document? What types of learning activities will you organise?

Improving engagement is not a contemporary issue. It has been an essential topic for Higher Education (HE) institutions and is a constant challenge for all of them. In learning environments, engagement has been formally defined as "learner's interest and participation in an educational initiative and is directly related to favourable educational outcomes including learning and behavioural change" (Carlson, 2020).

From those brief reflections, this topic aims to start a critical argument for higher education institutions creating tools to verify their alignments of engagement tools and creating an environment that allows communities of practice to develop and engage all the members involved. Those reflections are systematised in section 3 .

The following section discusses the Contemporaine perspective while this research has been conducted, the virtual classes post the Covid-19 pandemic. Its challenging approaches and the new way of perceiving student engagement in a mandatory virtual moment are being highlighted to contextualise the final arguments.

\subsection{Virtual Classes Post the Covid-19 Pandemic}

The outbreak of Covid-19 pandemic throughout the world and closure of schools and universities have made all physical, academic sessions completely cease and shift to emergency remote teaching (Noor et al., 2020; Sepulveda-Escobar \& Morrison, 2020; United Nations Educational Scientific and Cultural Organization (UNESCO), 2020) 
Since then, enrolment in courses taught via videoconferencing programs has been on the rise in higher education (Castelli \& Sarvary, 2021) where faculty and students had to adapt to this unprecedented challenge transition and abrupt change in the delivery of the curriculum (Bao, 2020; Neuwirth, Jovic, \& Mukherji, 2020; Usak, Masalimova, Cherdymova, \& Shaidullina, 2020).

Many studies have proven that poor attendance of students, a decrease of educational experience, less participation and engagement in the classes and with the lectures, maintenance of appropriate online learning behaviours and etiquette in class are major problems resulting during online classes (Basal \& Eryilmaz, 2021; Castelli \& Sarvary, 2021; Neuwirth et al., 2020; Noor et al., 2020). According to Noor et al. (2020) "online classes have not gained the power to engage the students and keep them motivated, focused, and concentrated on their studies". One example is the cameras not being turned on during synchronous class meetings held via videoconferencing programs, as exposed by Castelli and Sarvary (2021).

Additionally, improper environment, inequality in the availability of gadgets, insufficient online study material, no access or slow internet speed" as well as health problems (Noor et al., 2020) have negatively influenced students' participation engagement with active learning. The results of Sepulveda-Escobar and Morrison (2020) indicated that "factors such as the lack of direct interaction with learners and the sudden change of setting were among those that most strongly affected the participants' own learning process".

In their turn, Daniels et al. (2021) found that engagement, achievement of goals, and students' perception of success significantly decreased in remote learning. At the same time, Bao (2020) has pointed problems such as ack of self-discipline, suitable learning materials, or good learning environments when the students are self-isolated at home.

Neuwirth et al. (2020) brought up some concerning questions about the topic: "How can students truly participate in a virtual classroom if they do not have computers, reliable wireless connectivity, quiet spaces and free time away from taking care of family members?" or "How should faculty approach maintaining rigour and delivering quality education as well as support their students' ongoing ability to engage in meaningful, interactive educational activities in the context of a crisis such as this pandemic?". In summary, higher education institutions are pushed to develop strategies and approaches to overcome these problems and meet the needs of the students and the tutors who have always been teaching and have been familiar with faceto-face methods. Not to say that, many instructors have likely never taught online before the pandemic (Wilson et al., 2021).

Mahmood (2021) has presented several instructional strategies that can help design successful online study sessions and play a fundamental role in enhancing student learning, such as maintaining slow voice, practising vocal functions by teachers, getting feedback from students, and offering flexible feedback teaching and assessment policies. Recording online lectures and getting support from teaching assistants are also vital features.

In the same line, Bao (2020) has classified some instructional strategies that higher education institutions can apply to improve students learning concentration and engagement. Includes: making emergency preparedness plans for unexpected problems as online educational platforms may often be overloaded; dividing the teaching content into small units to help students focus; emphasising the use of the voice in teaching as body language and facial expressions are under restrictions in the virtual environment; working with teaching assistants to have more support during the online classes; encouraging and strengthening students' active learning offline and combining online and offline self-learning effectively.

Basal and Eryilmaz (2021) suggested that engagement can be increased with the use of Web 2.0 technologies that create an "environment conducive to bring engagement with their participatory nature", while Daniels et al. (2021) recommends that faculty can provide students with choice and autonomy to support their engagement with the learner outcomes for the course.

Studies

Volume 4, Issue 4, pp. 137-143

2021

\section{Class Representatives' Role as a Strategy to Enhance Students' Engagement and Learning} Process in Virtual Classes in the Perspective of the Cops

Higher education institutions have a growing concern to manage student satisfaction and consider students as consumers. This consideration of students as consumers can be conducted beyond the perspective of delivering study and learning services and the relationship between students and institutions.

This study highlights the Communities of Practice (Wenger, 2009) as a concept used to understand social structures capable of reproducing and transforming knowledge and providing learning opportunities for its 


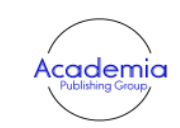

International Journal of Educational Studies

Volume 4, Issue 4, pp. 137-143

2021

DOI: $10.53935 / 2641-533 x . v 4 i 4.165$

"Corresponding Author: Christiane Bellucci

Email: bellucci.christiane@oxfordbusinesscollege.ac.uk Funding: This study received financial support from Oxford Business College.

Article History:

Received: 15 October 2021

Revised: 8 November 2021

Accepted: 29 November 2021

Published: 21 December 2021

(C) 2021 by the authors: licensee Academic

Publishing Group members. Their source of coherence is found in their practices and modes of action sustained over time by the community involved, marked by a strong commitment that enables participants to carry out an initiative they value and, thus, promote a joint learning partnership.

This initial reflection tries to connect the role of the class representatives as one agent of this relationship required by CoPs. Therefore, general governance strategies involving students can provide effective results for higher education institutions. In this way, the approach couples the activities of class representatives as a vehicle for engagement, and consequently, learning.

In a theoretical approach, it can be interpreted that, from the attitude and involvement of class representatives, the learning process occurs through the trajectories of participation in communities of practice in the negotiation of meanings and legitimisation of knowledge. This process allows the personal transformation and construction of the identity of the participants, being them directly involved, as class representatives, as those indirectly involved, as represented students and staff members of educational institutions. Due to its ability to encourage the production and reproduction of knowledge, communities of practice have gained space in scientific research in Higher Education.

Keeping the theoretical reflection, it is also possible to apply this approach to the action of class representatives in communities of practice in a virtual context. Even more challenging, this environment has become the main avenue of communication and decision-making in past year educational institutions in the UK. As contextualised, the virtual environment took place in a pandemic context and was established as a mandated response in several organisations to keep their activities running.

When formatting an idea of how students may behave on their learning and engagement perspective, the outcome is usually a general concept of students in classrooms, with teachers, textbooks and homework. It is possible to face various approaches to reach each student's right individual learning style to achieve the successful learning process targeted. All those approaches are significant for learning techniques and help educators organise their learning environment.

Observing organisational and social theories also shows a perspective from the role of the top decision makings in higher education institutions to encourage students engagement. This role comes from governance attitudes in the management process. The CoPs approach brings the social perspectives of engagement, but providing a rich environment for practice communities comes from management decisions.

Therefore, the first step of this reflection urges us to understand the organisational level of these actions. Furthermore, maybe the CoPs approach brigs us some perspectives. How can higher education institutions provide an environment for class representatives to become engagement vehicles?

The previous section mentioned the actions and strategies for virtual classes said the learning process and the focus on the students and teachers. However, after a forced demand for virtual classes during a pandemic, higher education institutions adapted diverse activities and increased the virtual environment to allow the continuity of teaching activities. This paper is the first step of a study at an organisational level and tries to understand the institutions' actions to provide an environment for communities of practices development, including class representatives.

After the first analysis and interpretations, a demand for a tool to evaluate this relation emerged. A checklist tool is required to help managers understand the main aspects of providing a community of practice from the organisational perspective. Consequently, it allows observing the students interactions and engagements on individual levels.

\section{Conclusions and Suggestions for Future Researches}

The purpose of this study was to answer the following research question: May class representatives impact students' behaviour in the sense of their engagement and learning in virtual classes context? By using the Community of Practice perspective as a concept to understand social structures capable of reproducing and transforming knowledge and providing learning opportunities for its members in the virtual environment post Covid-19 pandemic, we found that class representatives can play a relevant role by increasing engagement and facilitating the students' learning.

Based on the previous section reflection, our subsequent research question would be: How can Higher education institutions provide a high engagement environment, based on the communities of practice perspective, using its governance strategies? 
In this topic, we propose a model that may be used as a guide for further studies. This guide is the first step of evaluation on the organisational level, how class representatives may lead the student's behaviours to an engagement in the virtual environment (Flint \& O’Hara, 2013; Gómez \& Suárez, 2021; Lizzio \& Wilson, 2009; Wenger, 2009).

Table-1.Governance strategies for engagement in higher education.

\begin{tabular}{|c|c|c|}
\hline Dimension & $\begin{array}{l}\text { Organisational concern } \\
\text { (that may focus on class representatives) }\end{array}$ & Target \\
\hline Ownership & $\begin{array}{l}\text { Are we sharing our goals? } \\
\text { Are we delegating responsibilities? } \\
\text { Are we allowing participation? } \\
\text { Do we accept diversity? }\end{array}$ & $\begin{array}{l}\text { Share ownership } \\
\text { Sense of belonging }\end{array}$ \\
\hline Community & $\begin{array}{l}\text { What is expected (from groups, staff, } \\
\text { department)? } \\
\text { Are all areas being encouraged? } \\
\text { Did we create appropriate feedback channels? }\end{array}$ & $\begin{array}{l}\text { A high level of attention given } \\
\text { Standards, roles and expectations } \\
\text { well organised } \\
\text { Increasing the learning process }\end{array}$ \\
\hline Practice & $\begin{array}{l}\text { Does everyone know our history? } \\
\text { Do we develop people? } \\
\text { Do people learn from each other? }\end{array}$ & $\begin{array}{l}\text { Historical records } \\
\text { Internal staff development } \\
\text { Recognised success }\end{array}$ \\
\hline Individual actions & $\begin{array}{l}\text { How much satisfied are our people? (staff, } \\
\text { student, all academic community) } \\
\text { Do people feel that there is an opportunity for } \\
\text { self-development? }\end{array}$ & $\begin{array}{l}\text { Individual recognition } \\
\text { Individual satisfaction } \\
\text { Individual growth }\end{array}$ \\
\hline
\end{tabular}

For future research, the suggestion is to evaluate the actions of a community of practice environment to understand the actual moment or the future strategies of that institution, based on the organisational concerns. And after that, create a tool to evaluate the engagement and participation aspects on an individual level.

Moreover, there are two limitations to be addressed in the study. The first one is concerned with the methods in which research and results could have benefited from a qualitative case study with interviews and observation as data collection techniques. A second limitation, as the study focused on students' behaviour, left out some other approaches such as organisational culture and strategic decisions made by higher education institutions.

\section{References}

Akinyemi, A. F., Rembe, S., Shumba, J., \& Adewumi, T. M. (2019). Allocation of time in communities of practice: A strategy to enhance continuing professional teachers' development of high schools teachers'. Cogent Social Sciences, 5(1), 1583629. Available at: https://doi.org/10.1080/23311886.2019.1583629.

Bao, W. (2020). Covid-19 and online teaching in higher education: A case study of Peking University. Human Behavior \& Emerging Technologies, 2,113-115. Available at: https://doi.org/10.1002/hbe2.191.

Basal, A., \& Eryilmaz, A. (2021). Engagement and affection of pre-service teachers in online learning in the context of COVID 19: Engagement-based instruction with web 2.0 technologies vs direct transmission instruction. Journal of Education for Teaching, 47(1), 131-133. Available at: https://doi.org/10.1080/02607476.2020.1841555.

Bond, M. A., \& Lockee, B. B. (2018). Evaluating the effectiveness of faculty inquiry groups as communities of practice for faculty professional development. Journal of Formative Design in Learning, 2(1), 1-7. Available at: https://doi.org/10.1007/s41686018-0015-7.

Carlson, E. R. (2020). COVID-19 and educational engagement. Journal of Oral and Maxillofacial Surgery, 78(7), 1049-1051.

Castelli, F. R., \& Sarvary, M. A. (2021). Why students do not turn on their video cameras during online classes and an equitable and inclusive plan to encourage them to do so. Academic Practice in Ecology and Evolution, 11, 3565-3576. Available at: https://doi.org/10.1002/ece3.7123.

Daniels, L. M., Goegan, L. D., \& Parker, P. C. (2021). The impact of COVID-19 triggered changes to instruction and assessment on university students' self-reported motivation, engagement and perceptions. Social Psychology of Education, 24, 299-318. Available at: https://doi.org/10.1007/s11218-021-09612-3.

Flint, A., \& O'Hara, M. (2013). Communities of practice and 'student voice': Engaging with student representatives at the faculty level. Student Engagement and Experience Journal, 2(1), 1-19. Available at: http://dx.doi.org/10.7190/seej.v1i1.64.

Gilson, L. L., \& Goldberg, C. B. (2015). Editors' comment: So, what Is a conceptual paper? Group \& Organization Management, 40(2), 127-130. Available at: https://doi.org/10.1177/1059601115576425. 
Gómez, R. L., \& Suárez, A. M. (2021). Extending impact beyond the community: Protocol for a scoping review of evidence of the impact of communities of practice on teaching and learning in higher education. International Journal of Educational Research Open, 2-2, 100048. Available at: https://doi.org/10.1016/j.ijedro.2021.100048.

Jaakkola, E. (2020). Designing conceptual articles: Four approaches. AMS Review, 10, 18-26. Available at: https://doi.org/10.1007/s13162-020-00161-0.

Lave, J., \& Wenger, E. (1991). Situated learning: Legitimate peripheral participation. New York: Cambridge University Press.

Lizzio, A., \& Wilson, K. (2009). Student participation in university governance: The role conceptions and sense of efficacy of student representatives on departmental committees. Studies in Higher Education, 34(1), 69-84. Available at: https://doi.org/10.1080/03075070802602000.

Mahmood, S. (2021). Instructional strategies for online teaching in Covid-19 Pandemic. Human Behaviour \& Emerging Technology, 3, 199-203. Available at: https://doi.org/10.1002/hbe2.218.

Neuwirth, L. S., Jovic, S., \& Mukherji, B. R. (2020). Reimagining higher education during and post-COVID19: Challenges and opportunities. Journal of Adult and Continuing Education, 1-16. Available at: https://doi.org/10.1177/1477971420947738.

Noor, S., Ali, M. N., \& Husnine, S. M. (2020). Performance of online classes in Lahore, pakistan during Covid-19. International Society for Performance Improvement, 59(9), 33-42. Available at: https://doi.org/10.1002/pfi.21938.

Pyrko, I., Dörfler, V., \& Eden, C. (2019). Communities of practice in landscapes of practice. Management Learning, 50(4), 482-499. Available at: https://doi.org/10.1177/1350507619860854.

Scagnoli, N. I., Choo, J., \& Tian, J. (2019). Students' insights on the use of video lectures in online classes. British Journal of Educational Technology, 50(1), 399-414. Available at: https://doi.org/10.1111/bjet.12572.

Sepulveda-Escobar, P., \& Morrison, A. (2020). Online teaching placement during the COVID-19 pandemic in Chile: Challenges and opportunities. European Journal of Teacher Education, 43(4), 587-607. Available at: https://doi.org/10.1080/02619768.2020.1820981.

United Nations Educational Scientific and Cultural Organization (UNESCO). (2020). Global education coalition for COVID-19 response. UNESCO. Retrieved from https://en.UNESCO.org/covid19educationresponse/globalcoalition. [Accessed July 1, 2021]

Usak, M., Masalimova, A. R., Cherdymova, E. I., \& Shaidullina, A. R. (2020). New playmaker in science education: COVID-19. Journal of Baltic Science Education, 19(2), 180-185. Available at: https://doi.org/10.33225/jbse/20.19.180.

Wenger, E. (2009). A social theory of learning. In: Illeris, K. (Ed.), Contemporary Theories of Learning: Learning Theorists in their own words (pp. 209-218). London: Routledge.

Wenger, E., McDermott, R., \& Snyder, W. (2002). Cultivating communities of practice: A guide to managing knowledge. Boston, MA: Harvard Business School Press.

WHO. (2020). World health organization. Retrieved from https://www.who.int/southeastasia/outbreaks-and-emergencies/novelcoronavirus-2019. [Acessed July 1, 2021].

Wilson, J. L., Hensley, A., Culp-Roche, A., Hampton, D., Hardin-Fanning, F., \& Thaxton-Wiggins, A. (2021). Transitioning to teaching online during the COVID-19 pandemic. SAGE Open Nursing, 7, 23779608211026137. Available at: https://doi.org/10.1177/23779608211026137.

\footnotetext{
International Journal of Educational Studies

Volume 4, Issue 4, pp. 137-143

2021

DOI: $10.53935 / 2641-533 x . v 4 i 4.165$

Corresponding Author: Christiane Bellucci

Email: bellucci.christiane@oxfordbusinesscollege.ac.uk

Funding: This study received financial support

from Oxford Business College.

Article History:

Received: 15 October 2021

Revised: 8 November 2021

Accepted: 29 November 2021

Published: 21 December 2021

(C) 2021 by the authors; licensee Academic

Publishing Group
} 